\title{
Study of Confinement Improvement in Presence of a MARFE in the HT-7 Superconducting Tokamak
}

\author{
M. Asif ${ }^{a, b}$, and the HT-7 Team \\ a Institute of Plasma Physics, Chinese Academy of Sciences, P.O. Box 1126, Hefei, Anhui 230031, P. R. China \\ ${ }^{b}$ Applied Physics Division, PINSTECH, Islamabad 04770, Pakistan
}

Received on 24 May, 2006

\begin{abstract}
A new set of actively cooled toroidal double-ring graphite limiters have been developed on the HT-7 tokamk for long pulse operation. In this paper, a Multifaceted asymmetric radiation from the edge (MARFE) phenomena and improved particle confinement induced by a MARFE, characterized by $\mathrm{H}_{\alpha}$ line emissions drops and the lineaveraged density increase have been studied in the HT-7 ohmic discharges (where the plasma current $\mathrm{I}_{p}=145$ $\mathrm{kA}$, loop voltage $\mathrm{V}_{\text {loop }}=2-3 \mathrm{~V}$, toroidal field $\mathrm{B}_{T}=1.7 \mathrm{~T}$, and $Z_{\text {eff }}=2-8$ ). It is found that the improved particle confinement phase exists for about $90 \mathrm{~ms}$ and the particle confinement time $\tau_{P}$ increased about 1.6 times.
\end{abstract}

Keywords: Confinement Improvement; Graphite limiters; MARFE

\section{INTRODUCTION}

Operating at high density, the MARFE phenomenon usually develops before reaching the density limit. The term 'MARFE' [1,2] is an acronym for 'multifaceted asymmetric radiation from the edge' and defines a toroidally symmetric and poloidally asymmetric belt of high density, strongly radiating, cold plasma localized at the high field side of a limiter tokamak. In some cases, the MARFE can extend all around the poloidal cross-section, thus detaching the main hot plasma from the first wall. The phenomenon is of interest both as a precursor of the density limit and, because of its capability of radiating power, as a means of reducing localized thermal loads on the wall of a fusion reactor. MARFE phenomena has been observed on many tokamaks $[1,3]$.

In the TEXTOR-94 limiter tokamak, the highest critical density can be obtained up to $130-200 \%$ of the Greenwald density limit $\mathrm{n}_{G W}[4]$, (for circular plasmas: $\mathrm{n}_{G W}=\mathrm{I}_{P} / \pi \mathrm{a}^{2}$, where $\mathrm{n}_{G W}$ is the line-averaged density in units of $10^{20} \mathrm{~m}^{-3}$ ), by the controlled localized recycling [5]. In the Tore Supra superconducting tokamak [6], the critical density is only 12 $22 \%$ of the Greenwald limit. In the HT-7 superconducting tokamak, the averaged density of MARFE onset $\left(\mathrm{Z}_{e f f}=3-8\right.$ and $15-30 \%$ of the Greenwald limit [7-8]) is also observed to be very low in the discharges of each campaign before the wall conditioning [9-10]. However, after rf- boronization in the HT-7 [10], the MARFE onset density is more than $120 \%$ of $\mathrm{n}_{G W}$ [7-8]. With good wall conditioning (e.g., fresh siliconization and fresh boronization) in the TEXTOR-94 [11], the appearance of MARFE's has been postponed up to $170 \%$ of the Greenwald limit. The critical conditions for the occurrence of a MARFE may be correlated to the edge plasma parameters, because it is a localized instability within the edge region. It was evidence that the critical value of $\mathrm{n}_{e}(0.7 \mathrm{a}) \mathrm{Z}_{e f f}$ in the MARFE onset always correlated with the total input power which has been observed in the FTU [12] and the HT-7 limiter tokamak [7-8], here $\mathrm{n}_{e}(0.7 \mathrm{a})$ is the line average density, measured at the outermost interferometer channel at $\mathrm{r}=20 \mathrm{~cm}$ $(\mathrm{r}=0.7 \mathrm{a}$, the minor radius $\mathrm{a}=27 \sim 28 \mathrm{~cm})$. In the TEXTOR94 , dependence of the edge electron density $(r=a+1 \mathrm{~cm})$ on the heating power was also observed [13]. Therefore, it suggests experimentally the importance of impurity radiation and localized power balance in the MARFE formation.

Experiments in the TFTR tokamak [14-16] illustrate the sequence of MARFE formation and evolution to a detached $\mathrm{H}-$ mode-like plasma: a MARFE triggered at some position on the inner periphery of the minor cross section of the plasma cools the plasma edge further causing the minor radius to shrink and the plasma to thus pull away from the walls and limiters. In the detached state the electron temperature and density profiles are narrower and $\sim 100 \%$ of the input power is radiated away by impurities in the edge layer. In the TEXTOR tokamak the MARFE generally leads to a disruption. In the FTU tokamak the onset of a MARFE always occurs before achieving the density limit [12]. The critical density for its onset is not a constant for the same magnetic field and plasma current, but depends on the vacuum vessel conditioning procedure and on the material used for the limiter surface [17].

Many machines were operated for the mixed carbon material used for long pulse operation, ultimately steady state. The graphite based first wall components have been designed and tested to sustain particle and heat exhausts under steady state conditions in Tore Supra [18]. A major part of DIII-D [19] program is focused upon high performance experiments. HT-7 is a superconducting tokamak [20] with the limiter configuration designed to operate with high power and long duration discharge. The last closed flux surface was defined by the main poloidal limiter in 1999, which receives the highest heat loads and largest flux of energetic particles bombardment from the plasma. In past operations with Mo limiter, due to energetic particles bombardment and overheating problem, the plasma discharge was usually terminated by the very strong hard $\mathrm{X}$ ray radiation, hot spot and high- $Z$ impurities. In order to alleviate above problems, a new set of actively cooled toroidal double-ring graphite limiters [21], has been developed in the Hefei Tokamak-7 (HT-7) superconducting tokamak in 2004. The doped graphite GBST1308 with the dopant concentration of $1 \% \mathrm{~B}, 2.5 \% \mathrm{Si}, 7.5 \% \mathrm{Ti}$, (about $20 \%$ of first wall) was used as limiter material [21]. Very stable and reproducible discharges were obtained with significantly increased density and a large increase in the available pulse length, as com- 


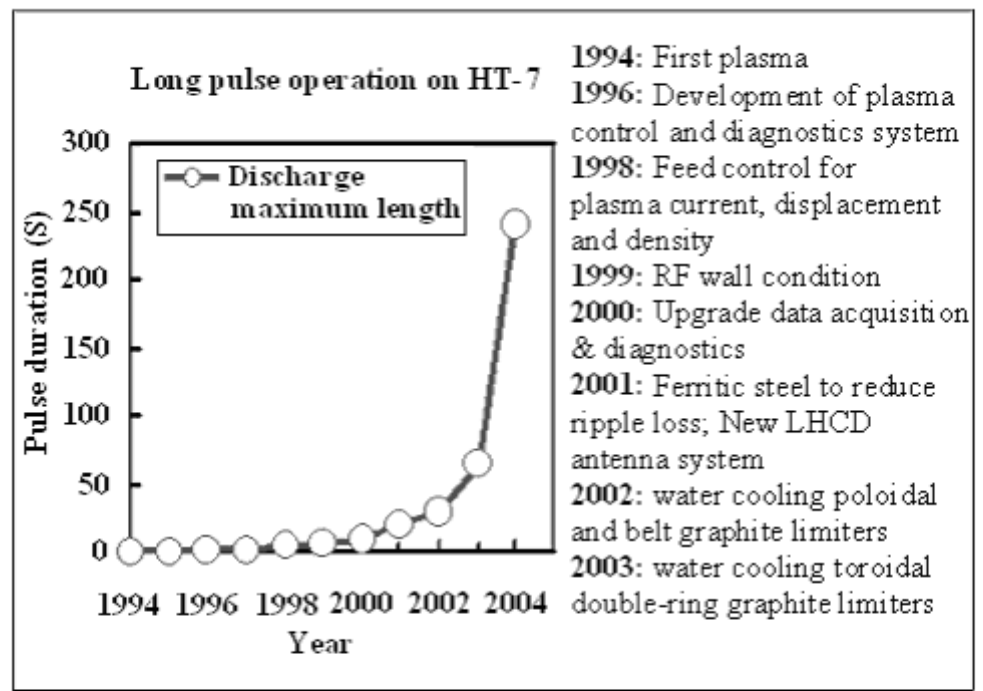

FIG. 1: Progress of long-pulse operation in the HT-7 tokamak.

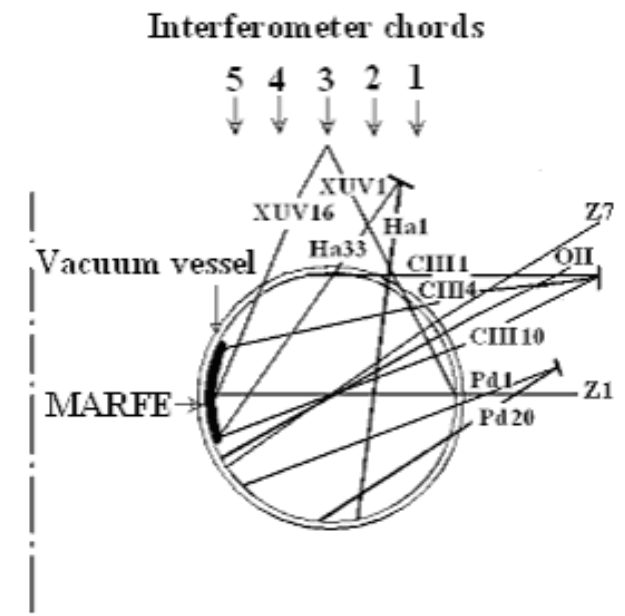

Torus axis

FIG. 2: A chord view of the vertical 5-channel HCN interferometer (from low field to high field at: $+20 \mathrm{~cm},+10 \mathrm{~cm}, 0 \mathrm{~cm},-10 \mathrm{~cm}$, $-20 \mathrm{~cm}$ ), 20-channel $\mathrm{H}_{\alpha}$ emission ( $\left.\mathrm{Pd} 1 \sim 20\right)$, 33-channel $\mathrm{H}_{\alpha}$ emission, 10-channel CIII emission, 7-channel bremsstrahlung emission (Z1 7), 16-channel XUV bolometer, one channel OII line emission chord in the HT-7 tokamak.

pared to Mo limiters. Up to $240 \mathrm{~s}$ of long pulse discharge has been achieved by lower hybrid current drive (LHCD) with new graphite limiters [22] in the HT-7 in 2004.

In this paper, a Multifaceted asymmetric radiation from the edge (MARFE) phenomena and improved particle confinement induced by a MARFE, characterized by $\mathrm{H}_{\alpha}$ line emissions drops and the line-averaged density increase have been studied in the HT-7 ohmic discharges (where the plasma current $\mathrm{I}_{p}=145 \mathrm{kA}$, loop voltage $\mathrm{V}_{\text {loop }}=2-3 \mathrm{~V}$, toroidal field $\mathrm{B}_{T}=1.7 \mathrm{~T}$, and $Z_{e f f}=2-8$ ). It is found that the improved parti- cle confinement phase exists for about $90 \mathrm{~ms}$ and the particle confinement time $\tau_{P}$ increased about 1.6 times.

\section{EXPERIMENTAL SETUP}

The Hefei Tokamak-7 (HT-7) is a superconducting tokamak [7-8, 21-26], and it was reconstructed from the original Russian T-7 tokamak in 1994. It has a major radius of $\mathrm{R}=$ $1.22 \mathrm{~m}$, minor radius of $\mathrm{a}=0.27 \mathrm{~m}$ in the circular cross section. There are two layers of thick copper shells, and between them are located 24 superconducting coils which can create and maintain a toroidal magnetic field $\left(\mathrm{B}_{T}\right)$ of up to $2.5 \mathrm{~T}$. Based on the understanding of plasma surface interactions, several technical improvements have been made recently. The new GBST1308 doped graphite was used as limiter material. All carbon titles were coated with $100 \mu \mathrm{m}$ Silicon Carbide ( $\mathrm{SiC}$ ) functional gradient coating [21]. The two poloidal water-cooling limiters and one toroidal water-cooling belt limiter at high field side were developed in 2002 [21]. A new set of actively cooled toroidal double-ring graphite limiters [22], at bottom and top of the vacuum vessel was developed for long pulse operation, and up to $240 \mathrm{~s}$ of long pulse plasma has been achieved in the HT-7 in 2004 as shown in Fig. 1.

The major research fields on the HT-7 are steady-state operation, high-performance such as advanced tokamak operation modes, the fuelling study [27] and MARFE phenomena [28], lower hybrid wave (LHW) current drive [29] and ICRF heating [30]. For recent experiments on the HT-7, the following main diagnostics signals are effectively used in this paper as shown in Fig. 2: a 16-channel XUV bolometer array to measure plasma radiation losses, a 7-channel bremsstrahlung emission $(\mathrm{Z} 1 \sim 7)$ to measure $\mathrm{Z}_{\text {eff }}$, a multichannel $\mathrm{H}_{\alpha}\left(\mathrm{D}_{\alpha}\right)$ radiation array for $\tau_{P}, 10$-channels CIII line emission, an impurity optical spectrum measurement system and the electron density profile measured by a vertical 5-channel far- 


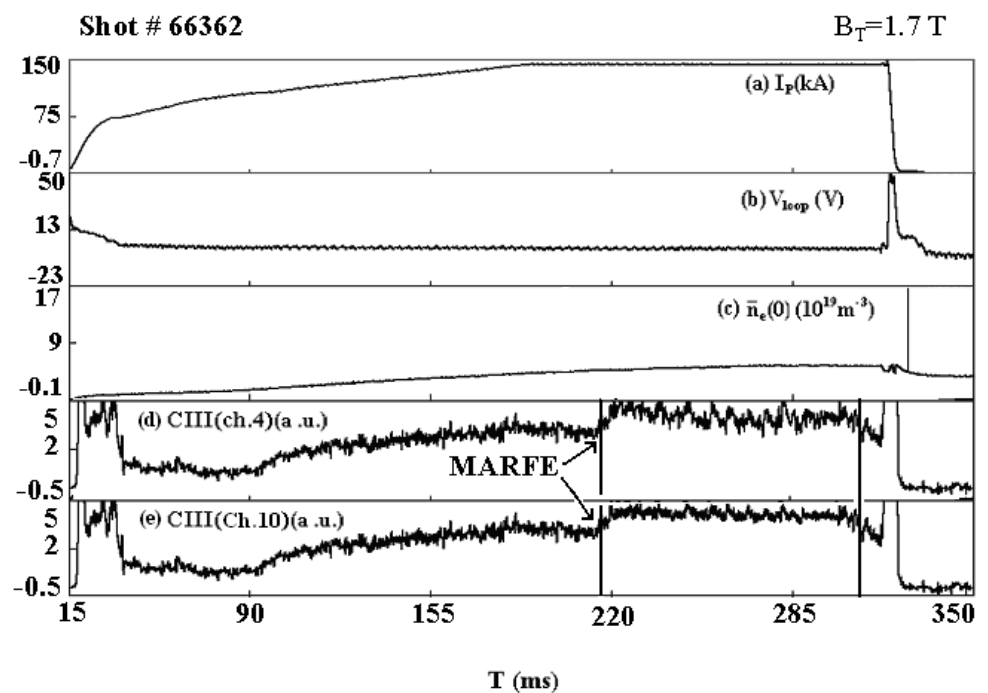

FIG. 3: The onset of a MARFE in the HT-7: (a) plasma current, (b) loop voltage, (c) line averaged electron density (vertical chord at $\mathrm{r}=0 \mathrm{~cm}$ ), (d) CIII emission from channel 4, (e) CIII emission from channel 10.

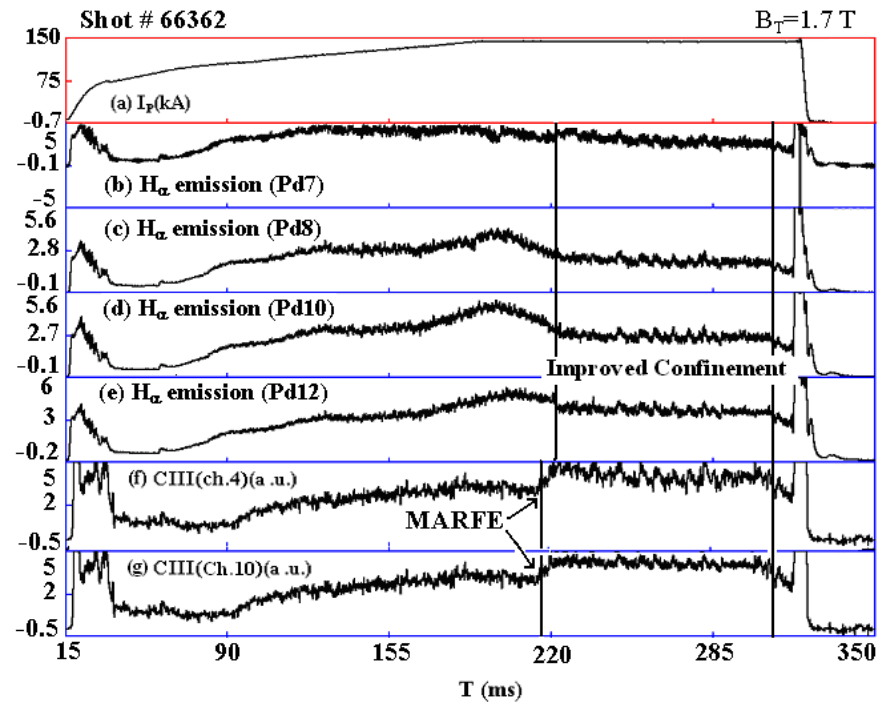

FIG. 4: The H-mode-like plasma: (a) plasma current, (b-e) multichannel $\mathrm{H}_{\alpha}$ emission (Pd7, Pd8, Pd10, Pd12), (f) CIII emission from channel 4, (g) CIII emission from channel 10.

infrared (FIR) hydrogen cyanide (HCN) laser interferometer [31-32]. The laser source used in the interferometer was a continuous-wave (CW) DC glow discharge HCN laser with $3.4 \mathrm{~m}$ cavity length and $100 \mathrm{~mW}$ power output at $337 \mu \mathrm{m}$ wavelength. The system has a temporal resolution of $0.1 \mathrm{~ms}$ with a $10 \mathrm{kHz}$ rotating grating [32].

\section{MARFE PHENOMENA AND IMPROVED PARTICLE CONFINEMENT}

The MARFE may lead to improved confinement by cooling the edge at some times. The observed sequence of events for the formation of the MARFE and subsequent evolution into a detached plasma is as follows [33]. As radiating impurities accumulate in the plasma edge, a poloidally uniform band of radiating impurities is formed; then, as the plasma density or impurity density is increased, the poloidally uniform band goes through a transition into a stable, poloidally asymmetric distribution of radiating impurities-the MARFE, still located 


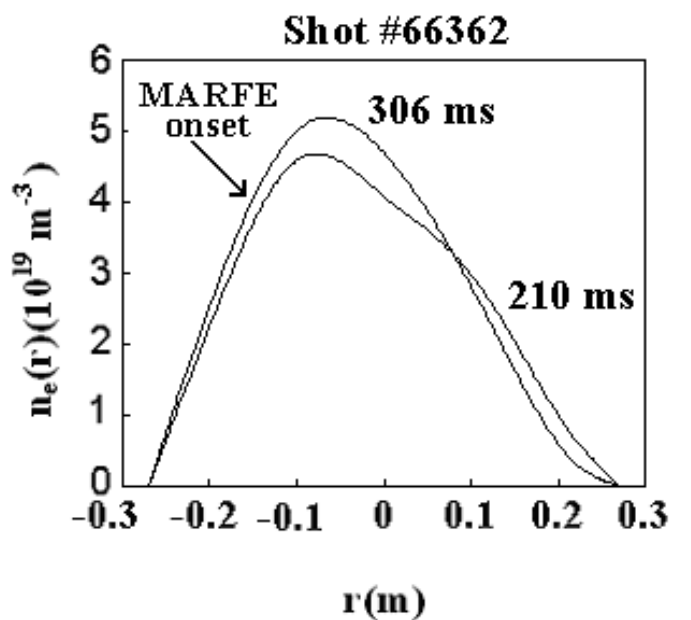

FIG. 5: Electron density profiles $\mathrm{n}_{e}(\mathrm{r})$ by Abel inversion, at $\mathrm{t}=210 \mathrm{~ms}$ (before the event trigger) and $\mathrm{t}=306 \mathrm{~ms}$ (before the end of improved confinement mode).

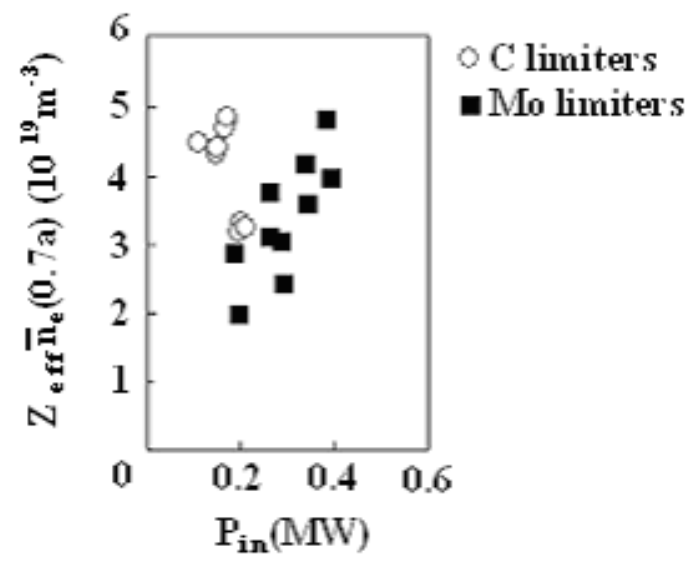

FIG. 6: The critical conditions for the MARFE activity with different limiter materials C and Mo in the HT-7 tokamak.

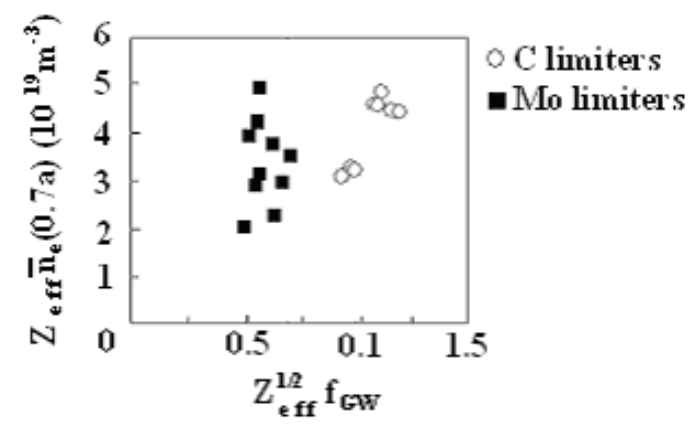

FIG. 7: MARFE occurs at values of $Z_{e f f}^{1 / 2} f_{G W}$ in the range of $0.9 \sim 1.2$ on new graphite limiters, where $f_{G W}=\frac{\bar{n}_{e}}{n_{G W}}$, (Here $\bar{n}_{e}$ is the maximum line average electron density and $n_{G W}$ is the Greenwald density).

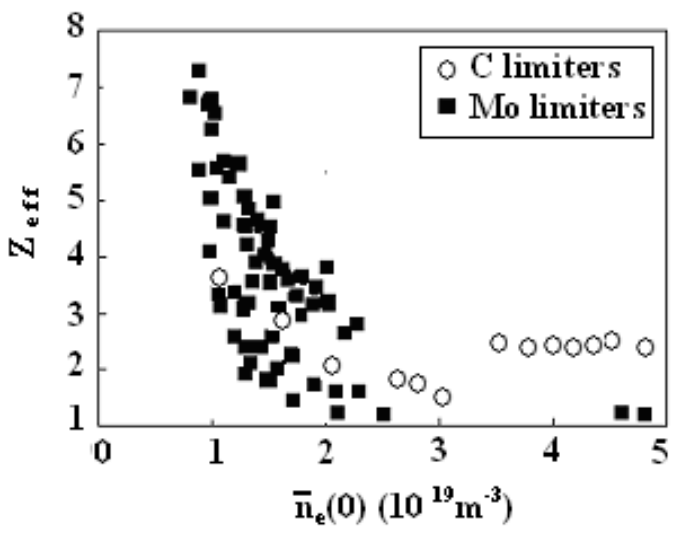

FIG. 8: Comparison of impurity content with graphite and molybdenum limiter materials, in the HT-7 tokamak.

in the plasma edge, which ultimately becomes highly localized in tokamaks. Then, as the plasma or impurity density is further increased, the impurities undergo a further transition back into a poloidally uniform band. Since the radiative cooling of the edge has been increasing with increasing density, in this final state the plasma is detached or nearly detached.

Figure 3 shows the typical shot of experimental campaign 2004 (shot No.66362) on HT-7 with graphite limiters, the plasma current about $145 \mathrm{kA}$, the loop voltage $\mathrm{V}_{\text {loop }}<2-3$ $\mathrm{V}$, the toroidal field $\mathrm{B}_{T}=1.7 \mathrm{~T}, \mathrm{Z}_{e f f}=2.5, \mathrm{R}=1.22 \mathrm{~m}, a=0.27$ $\mathrm{m}$, the electron temperature $\mathrm{T}_{e}=600 \mathrm{eV}$ and the line-averaged density about $5.4 \times 10^{19} \mathrm{~m}^{-3}$. A typical position of the MARFE on the HT-7 (shot No.66362) is identified by visible CIII (Channels 4 and 10) line emission as shown in Fig. 3. The MARFE occurs in the plasma column on the inner high field side. The MARFE onset is characterized by a sudden modification of visible CIII (Channels 4 and 10) line emission signal. It is clear that MARFE event occurs from $t=215 \mathrm{~ms}$ suddenly as shown in Fig. 3.

It must be mentioned that a radiatively improved confinement mode, on the HT-7 with molybdenum limiter has been observed [34-35], and the improved confinement mode phase is maintained for about $40 \mathrm{~ms}$. Fig. 4 shows the plasma current $\mathrm{I}_{p}$, multichannel $\mathrm{H}_{\alpha}$ emission (Pd7, $\left.\mathrm{Pd} 8, \mathrm{Pd} 10, \mathrm{Pd} 12\right)$, CIII emission from channels 4 and 10, in current experiments with graphite limiters on HT-7. It is found that the improved particle confinement phase, which is characterized by multichannel $\mathrm{H}_{\alpha}$ emission (Pd7, Pd8, Pd10, Pd12) drop and the line-averaged density increase, is observed clearly from $t=225$ $\mathrm{ms}$ in Fig. 4, exists for about $90 \mathrm{~ms}$ and the particle confinement time $\tau_{P}$ increased about 1.6 times.

Figure 3 (c) shows the core plasma central electron density increases during onset of improved particle confinement phase, and that if the neutral concentration increases, the MARFE density limit decreases, which were expected from the theory [36] has not measured by direct diagnostics on the HT-7 limiter tokamak.

The density profile is studied and shows that the profile become narrow and more peaked. Fig. 5 shows the electron den- 
sity profiles at $\mathrm{t}=210 \mathrm{~ms}$ (before the event trigger) and $\mathrm{t}=306$ $\mathrm{ms}$ (before the end of improved particle confinement phase). The particle confinement is improved and the density profile is clearly changed from $\mathrm{t}=210 \mathrm{~ms}$ to the improved particle confinement phase, $\mathrm{t}=306 \mathrm{~ms}$.

In the HT-7 superconducting tokamak with molybdenum limiter [8], the onset of a MARFE usually occurs in the early ohmic discharges $\left(\mathrm{Z}_{e f f}=3 \sim 8\right.$ and $15 \% \sim 25 \%$ of the $\left.\mathrm{n}_{G W}\right)$ of each experimental campaign before wall conditioning. In HT7 with graphite limiters [22], the critical density of MARFE onset is observed in the ohmic discharges $\left(\mathrm{Z}_{\text {eff }}=2 \sim 8\right.$ and $80 \% \sim 100 \%$ of the $\left.\mathrm{n}_{G W}\right)$. The best correlation has been found between the total input ohmic power and the product of the line average density, measured at the outermost interferometer channel at $\mathrm{r}=20 \mathrm{~cm}(\mathrm{r} / \mathrm{a} \cong 0.7$, the minor radius $\mathrm{a}=$ $27 \sim 28 \mathrm{~cm}$ ), and $\mathrm{Z}_{\text {eff }}$. Under same injected power, the critical density with graphite (C) limiters is much higher than Mo limiter [see Fig. 6].

In the HT-7 tokamak high- $Z_{e f f}$ discharges, it is found that the MARFE occurs at values of $\mathrm{Z}_{e f f}^{1 / 2} \mathrm{f}_{G W}=0.5 \sim 0.7$, where $f_{G W}=\frac{\bar{n}_{e}}{n_{G W}}$, (Here $\bar{n}_{e}$ is the maximum line average electron density and $n_{G W}$ is the Greenwald density), with molybdenum limiter [8]. The critical factor of MARFE onset is 0.9 $\sim 1.2$ with graphite limiters (see Fig. 7).

However in the HT-7 tokamak the occurrence of a MARFE is not only correlated with the density but also with $\mathrm{Z}_{e f f}$. A quantitative comparison of impurity reduction via density is shown in Fig. 8 for Mo and C limiter materials. The main impurities were reduced in case of graphite limiter. The density limit appeared to be connected with the impurity content [see Fig. 8] and the edge parameters, and the best results, signifi- cantly increased density and a large increase in the available pulse length (see Fig.1) were obtained. Moreover, Improved particle confinement phase induced by a MARFE were observed for about $90 \mathrm{~ms}$ [see Fig.4], and the particle confinement time $\tau_{P}$ increased about 1.6 times.

\section{CONCLUSIONS}

A new set of actively cooled toroidal double-ring graphite limiter has been developed in the HT-7 superconducting tokamak for long pulse operation. A Multifaceted asymmetric radiation from the edge (MARFE) phenomena and improved particle confinement induced by a MARFE, characterized by $\mathrm{H}_{\alpha}$ line emissions drops and the line-averaged density increase have been studied in the HT-7 ohmic discharges (where the plasma current $\mathrm{I}_{p}=145 \mathrm{kA}$, loop voltage $\mathrm{V}_{\text {loop }}=2-3 \mathrm{~V}$, toroidal field $\mathrm{B}_{T}=1.7 \mathrm{~T}$, and $Z_{e f f}=2-8$ ). It is found that the improved particle confinement phase exists for about $90 \mathrm{~ms}$ and the particle confinement time $\tau_{P}$ increased about 1.6 times. The results are similar to the experiments in TFTR [13], and are consistent with the theoretical explanation [33] given for the TFTR results. The MARFE cools the plasma edge, and the electron density profile is observed to become more narrow and peaked. In the HT-7, the occurrence of a MARFE is strongly correlated with the $Z_{e f f}$ and the wall condition but not with electron density.

\section{Acknowledgements}

The authors wish to thank the HT-7 team for cooperation during these experiments.
[1] B. J. Lipschultz, J. Nucl. Mater. 145-147, 15 (1987).

[2] N. Hosogane, N. Asakura, H. Kubo, K. Itami, A. Sakasai, J. Nucl. Mater. 196-198, 750 (1992).

[3] D. R. Baker, R. T. Snider, and M. Nagami, Nucl. Fusion 22, 807 (1982).

[4] M. Greenwald, J. L. Terry, S. M. Wolfe, S. Ejima, M. G. Bell, S. M. Kaye, and G. H. Neilson, Nucl. Fusion 28, 2199 (1988).

[5] P. C. De Vries, J. Rapp, F. C. Schuller, and M. Z. Tokar, Phys. Rev. Lett. 80, 3519 (1998).

[6] T. E. Evans, M.Goniche, A.Grosman, D.Guilhem, W. Hess, and J. C. Vallet, J. Nucl. Mater. 196-198, 421 (1992).

[7] X. Gao, Y. Jie, C. Xia, M. Wei, Y. Yang, S. Zhang, J. Zhao, L. Hu, Y. Zhu, J. Luo, Y. Zhao, N. Qiu, J. Li, B. Wan, G. Kuang, X. Zhang, X. Liu, X. Gong, Y. Bao, B. Lin, Z. Wu, Y. Li, Y. Shi, M. Song, P. Fu, X. Zhang, M. Zeng, A. Xie, N. Cui, H. Ruan, L. Wang, B. Sheng, S. Liu, W. Ye, K. Yang, J. Liu, Y. Cheng, H. Fan, S. Liu, X. Tong, J. Mao, X. Gu, J. Xie, and Y. Wan, Nucl. Fusion 40,1875 (2000).

[8] X. Gao, J. R. Luo, Y. P. Zhao, N. Qiu, Y. X. Jie, Y. Yang, C. Y. Xia, B. N. Wan, G. L. Kuang, X. D. Zhang, J. G. Li, F. X. Yin, X. N. Liu, X. Z. Gong, S. Y. Zhang, J. Y. Zhao, L. Q. Hu, Z. W. Wu, Y. D. Li, K. Yang, Y. Bao, W. W. Ye, L. Chen, H. Y. Fan, S. X. Liu, Y. F. Chen, B. L. Lin, Y. H. Xu, Y. J. Shi, M. Song, X. M. Zhang, M. S. Wei, M. Zeng, A. G. Xie, N. Z. Cui, H. L. Ruan, L. Wang, B. Sheng, S. Liu, X. D. Tong, X. M. Gu, J. S.
Mao, J. K. Xie, and Y. X. Wan, J. Nucl. Mater. 279, 330 (2000).

[9] J. K. Xie, Y. P. Zhao, J. Li, B. N. Wan, X. Z. Gong, J. S. Hu, X. Gao, X. M. Gu, S. D. Zhang, X. M. Wang, Y. Z. Mao, X. K. Yang, M. Zhen, S. Y. Zhang, and HT-7 team, J. Nucl. Mater. 290-293, 1155 (2001).

[10] J. Li, Y. P. Zhao, X. M. Gu, C. F. Li, B. N. Wan, X. D. Zhang, J. R. Luo, X. Z. Gong, J. K. Xie, Y. X. Wan, P. J. Qin, X. M. Wang, Y. D. Meng, S. F. Li, X. Gao, Y. Yang, D. Y. Xue, Y. Z. Mao, X. Den, L. Chen, Y. C. Fang, F. X. Yin, S. X. Liu, X. K. Yang, D. Zhen Xu, J. Y. Ding, Y. X. Jie, Q. C. Zhao, J. S. Mao, S. Y. Zhang, J. Y. Zhao, J. S. Hu, H. Y. Fan, M. S. Wei, B. L. Lin, G. X. Wang, Y. D. Fang, and W. C. Shen, Nucl. Fusion 39, 973 (1999).

[11] J. Rapp, W. Biel, H. Gerhauser, A. Huber, H. R. Koslowski, M. Lehnen, V. Philipps, A. Pospieszczyk, D. Reiser, U. Samm, G. Sergienko, M. Z. Tokar, and R. Zagórski, J. Nucl. Mater. 290293, 1148 (2001).

[12] D. Frigione, L. Pieroni, V. Zanza, G.M. Apruzzese, F. Alladio, M.L. Apicella, R. Bartiromo, M. Borra, G. Bracco, G. Buceti, P. Buratti, C. Centioli, M. Ciotti, V. Cocilovo, I. Condrea, F. Crisanti, R. de Angelis, B. Esposito, A. Frattolillo, G. Gatti, E. Giovannozzi, G. Granucci, M. Grolli, A. Imparato, H. Kroegler, M. Leigheb, L. Lovisetto, G. Maddaluno, G. Mazzitelli, P. Micozzi, S. Migliori, A. Moleti, F. Orsitto, D. Pacella, L. Panaccione, M. Panella, V. Pericoli-Ridolfini, S. Podda, G.B. 
Righetti, E. Sternini, A.A. Tuccillo, O. Tudisco, F. Valente, V. Vitale, and M. Zerbini, Nucl. Fusion 36, 1489 (1996).

[13] J. Rapp, P.C. De Vries, F.C. Schüller, M.Z. Tokar, W. Biel, R. Jaspers, H.R. Koslowski, A. Krämer-Flecken, A. Kreter, M. Lehnen, A. Pospieszczyk, D. Reiser, U. Samm, and G. Sergienko, Nucl. Fusion 39, 765 (1999).

[14] C. E. Bush, J. Schivell, J. D. Strachan, R. V. Budny, S. Cohen, B. Grek, A. Janos, D. W. Johnson, D. Manos, D. K. Mansfield, D. Mueller, H. H. Towner, R. M. Wieland and S. Yoshikawa, J. Nucl. Mater. 176-177, 792 (1990).

[15] J. D. Strachan, F. P. Boody, C. E. Bush, S. A. Cohen, B. Grek, L. Grisham, F. C. Jobes, D. W. Johnson, D. K. Mansfield, S. S. Medley, W. Morris, H. K. Park, J. F. Schivell, G. Taylor, K. L. Wong, S. Yoshikawa, M. C. Zarnstorff, and S. J. Zweben, J. Nucl. Mater. 145-147, 186 (1987).

[16] J. F. Schivell, C. E. Bush, D. K. Mansfield, S. S. Medley, H. K. Park, and F. J. Stauffer, Fusion Technol. 15, 1520 (1989).

[17] F. Alladio, M. L. Apicella, G. Apruzzese, E. Bartiromo, O. Borra, G. Bracco, G. Buceti, P. Buratti, C. Centioli, M. Ciotti, V. Cocilovo, I. Condrea, F. Crisanti, R. DeAngelis, B. Esposito, C. Ferro, G. Franzoni, D. Frigione, L. Gabellieri, E. Giovannozzi, G. Granucci, M. Grolli, A. Imparato, H. Kroegler, M. Leigheb, L. Lovisetto, G. Maddaluno, G. Mazzitelli, P. Micozzi, A. Moleti, F. Orsitto, L. Panaccione, D. Pacella, M. Panella, V. Pericoli, L. Pieroni, S. Podda, G. B. Righetti, F. Romanelli, S. E. Segre, E. Sternini, A. A. Tuccillo, O. Tudisco, F. Valente, V. Vitale, R. Zagorski, V. Zanza, and M. Zerbini, Plasma Phys. Control. Fusion 36, B253 (1994)

[18] M. Lipa, P. Chappuis, and P. Deschamps, Fusion Technol. 19, 2041 (1991).

[19] G. L. Jackson, D. R. Baker, K. L. Holtrop, S. Konoshima, R. Maingi, G. M. Staebler, and W. P. West, J. Nucl. Mater. 220222, 173 (1995).

[20] X. Gao, Y. X. Jie, Y. Yang, C. Y. Xia, M. S. Wei, S. Y. Zhang, Y. F. Cheng, L. Q. Hu, J. S. Mao, X. D. Tong, B. N. Wan, G. L. Kuang, J. G. Li, Y. P. Zhao, J. R. Luo, N. Qiu, K. Yang, G. Li, J. K. Xie, and Y. X. Wan, Phys. Plasmas 7, 2933 (2000).

[21] X. Gao, J. Li, Y. Yang, J. K. Xie, J. R. Luo, J. Y. Zhao, X. Z. Gong, L. Q. Hu, X. D. Zhang, Y. J. Shi, B. N. Wan, K. Tanaka, R. Sakamoto, Y. P. Zhao, G. L. Kuang, J. S. Hu, M. Asif, Y. X. Jie, H. Q. Liu, J. Liu, Q. Xu, L. Gao, and the HT-7 Team, J. Nucl. Mater. 337-339, 835 (2005).
[22] M. Asif, X. Gao, J. Li, G. L. Kuang, B. N. Wan, Y. X. Jie, J. Y. Zhao, X. D. Zhang, H. Q. Liu, X. D. Tong, J. Liu, Q. Xu, J. S. Hu, Y. Yang, B. Shen, J. S. Mao, L. Q. Hu, Z. W. Wu, B. L. Ling and HT-7 Team, Phys. Plasmas 12, 082502 (2005).

[23] M. Asif, X. Gao, J.G. Li, B.N. Wan and HT-7 Team, Phys. Lett. A. 336, 61 (2005).

[24] M. Asif, X. Gao, J.G. Li, B.N. Wan and HT-7 Team, Phys. Lett. A. 342, 175 (2005).

[25] M. Asif, X. Gao and HT-7 Team, Phys. Lett. A. 346, 305 (2005).

[26] M. Asif, X. Gao and HT-7 Team, Phys. Lett. A. 349, 250 (2006).

[27] Y. Yang, Y. Bao, J. Li, X. Gu and Y. He, Nucl. Fusion 39, 1871 (1999).

[28] X. Gao and HT-7 Team, Plasma Sci. Technol. 1, 25 (1999).

[29] G. Kuang, Y. Liu, J. Shan, W. Xu, X. Zhang, D. Liu, F. Liu, Y. Zhu, C. Zhang, G. Zheng, J. Wu, J. Lin, B. Ding, H. Xu, Y. Fang, J. Li, J. Luo, X. Zhang, B. Wan, Q. Zhao, J. Mao, X. Gao, S. Zhang, C. Li, X. Gu, P. Qing, H. Fan, S. Liu, B. Ling, B. Ding, Y. Li, Z. Wu, Y. Jie, S. Liu, J. Xie, and Y. Wan, Nucl. Fusion 39, 1769 (1999).

[30] Y. P. Zhao J. Li, J. K. Xie, Y. D. Meng, X. C. Wu, Y. X. He, D. Y. Xue, X. Deng, and Y. G. Shao, Chin. Phys. Lett. 14, 916 (1997).

[31] X. Gao, H. J. Lu, Q. L. Guo, Y. X. Wan, and X. D. Tong, Rev. Sci. Instrum. 66, 139 (1995).

[32] Y. X. Jie, X. Gao, Y. F. Cheng, K. Yang, and X. D. Tong, Int. J. Infrared Millimeter Waves 21, 1375 (2000).

[33] W. M. Stacey, Phys. Plasmas 3, 2673 (1996).

[34] X. Gao, Y. P. Zhao, J. R. Luo, Y. X. Jie, X. Z. Gong, B. N. Wan, J. G. Li, F. X. Yin, G. L. Kuang, X. D. Zhang, S. Y. Zhang, N. Qiu, X. N. Liu, J. Y. Zhao, Y. Yang, Y. Bao, B. L. Lin, Z. W. Wu, Y. D. Li, Y. H. Xu, K. Yang, G. X. Wang, W. W. Ye, L. Chen, Y. J. Shi, M. Song, X. M. Zhang, P. J. Qin, X. M. Gu, N. Z. Cui, H. Y. Fan, S. X. Liu, Y. F. Chen, L. Q. Hu, J. S. Hu, C. Y. Xia, H. L. Ruan, X. D. Tong, J. S. Mao, J. K. Xie, and Y. X. Wan, Plasma Phys. Control. Fusion 41, 1349 (1999).

[35] X. Gao, J. K. Xie, Y. X. Wan, K. Ushigusa, B. N. Wan, S. Y. Zhang, J. Li, and G. L. Kuang, Phys. Rev. E 65, 017401 (2001).

[36] W. M. Stacey, Plasma Phys. Control. Fusion 39, 1245 (1997). 